\title{
The Infection of COVID-19 among Health Care Workers in Dharmais Cancer Hospital
}

\author{
Mutiara Adelina ${ }^{1 *}$, Fifi Dwijayanti ${ }^{2}$ \\ ${ }^{1}$ Infection Prevention and Control Department, Dharmais Cancer Hospital - National Cancer Center, Jakarta, Indonesia \\ ${ }^{2}$ Research and Development Department, Dharmais Cancer Hospital - National Cancer Center, Jakarta, Indonesia
}

Infectious diseases are one of the biggest threats to humans. Currently, the world is in an outbreak condition caused by the SARS-CoV-2 virus started in Wuhan, China, in December 2019. This disease spread rapidly throughout the world and was announced as a pandemic by the World Health Organization (WHO) on March 11, 2020 [1]. Globally, the infected number of SARS-CoV-2 was over 84 million people and caused over 1 million death cases in December 2020. In Indonesia, there were more than 800,000 infectious cases and 23,000 death cases, with the highest cases in Jakarta in December 2020 [2].

This virus can be transmitted in two ways, such as direct contact (cough, sneeze, and droplet inhalation) and contact transmission (contact with oral, nasal, and eye mucous membranes) of a person with COVID-19 [3]. The current condition of the COVID-19 pandemic makes various challenges in the prevention and control of infections in hospitals. In this case, health care workers (HCWs) have been providing care to suspected, probable, or confirmed COVID-19 patients that make them in high-risk condition. Several studies have indicated that many HCWs had been infected with SARSCoV-2 in many hospitals worldwide [4-6].

In China, HCWs accounted for 3.8\% (1,716 cases) of 44,672 COVID-19 cases (PCR-confirmed) diagnosed until February 11, 2020 [7]. A study in Turkey reported that the positivity rates of SARS-CoV-2 among physicians, nurses, cleaning personnel, and the other occupations were $6.3 \%, 8.0 \%, 9.1 \%$, and $2.6 \%$, respectively. In Italy and the Netherlands, cases of COVID-19 in HCWs were under $10 \%$ (9.0\% vs. $6.4 \%)$, but in Washington, the cases were high, around $29.9 \%$ [8-10]. Furthermore, HCWs experience significant burdens from coronavirus infections, including SARS-CoV-2. The use of Personal Protective Equipment (PPE) and the training of infection control are associated with decreased infection risk, and specific exposures are correlated with increased risk. Hence, research is urgently needed on optimal methods for reducing $\mathrm{HCW}$ risk for SARS-CoV-2 infections [5].

Specifically, the COVID-19 units had more higher infection rate than other units that did not work in COVID-19 (8.3\% vs. 3.4\%) [6]. Dharmais Cancer Hospital is a tertiary referral hospital for cancer patients throughout Indonesia. In this hospital, the infection rate in HCWs (clinicians and nurses) and non HCWs (administration or other occupations that are not caring for patients directly) increased in November (51 cases) and December (92 cases). In December, the highest incidence rate was $5.8 \%$ (Figure 1 ) due to some holidays in that month. It showed that there was an increase in COVID-19 cases during holidays. Many other hospital services were delayed because of the limitations in various ways during the pandemic. The institution limited the number of patients who came to the hospital to prevent disease transmission. However, some service units still had overcrowding by patients, such as emergency units and inpatients units. It made the HCWs work overload and cause fatigue so that the immune system decreased.

Moreover, the transmission of COVID-19 to HCWs was influenced by various factors that increase infection risk. In early February 2020, researchers reported that transmission of COVID-19 among HCWs is related to overcrowding, lack of isolation room, and environmental contamination [11]. Studies in China, Singapore, Italy, Taiwan, and the USA stated that risk factors among health workers were lack of PPE, exposure to infected patients, overwork, poor infection control, and preexisting condition [12-16]. In Turkey, the emergence of SARS-CoV-2 due to positive person in the household $(P=.016)$, inappropriate use of personnel protective equipment while caring for patients with COVID-19 infection $(P=.003)$, staying in the same personnel break room without a medical mask for more than 15 minutes $(P=.000)$, and failure to keep a safe social distance from an HCWs $(P=.003)$ were statistically significant as risk factors for infection [6]. Based on the researchers' observation, exposure to infected patients, the incorrect technique of removing PPE, and working overload were three important COVID-19 risk factors among HCWs. Besides, in the non-HCWs, the risk factors infected with COVID-19 were throughout eating together and low personal hygiene.

The WHO has released interim guidance on HCWs risk assessment and management in the interest of COVID-19 offered for both the HCWs and their facilities [17]. Besides, the Ministry of Health has published guidelines for the prevention and control of Corona Virus (COVID-19) in Indonesia [18]. Although these 
guidelines are available, occupational health policymakers need to adapt procedures based on available resources and information. Dharmais has been trying various ways to decrease the positive rate of HCWs and other occupations. It set out all visitors who would come into the hospital for screening. It has also carried out several ways to control and prevent the transmission of COVID-19, for example, screening posts, monthly rotation of hours and workplaces, and limiting the number of patients at outpatient and inpatient. Besides, non HCWs who are not in direct contact with patients can work from home and consult with the doctor by teleconference (Regulatory based on No: UM.01.05/2.1/4473/2020).

The protection of health workers is essential despite increasing demand and the global shortage of PPE. In this case, the government needs to accelerate procurement and devise strategic use of available PPE to ensure adequate PPE availability for all HCWs. The strategic use of PPE can take the form of protracted wear and reuse of the PPE such as gowns or masks, especially in low-risk hospital departments in developing countries. For HCWs, they should be competent in the proper way to put on and take off PPE to prevent contamination. Besides, management and administration staff need to change their habits during a pandemic, such as wearing masks in the workspace, keeping a safe physical distance, and not eating together. Further research is required about the risk factors of transmission COVID-19 in the hospital.

The Government in Jakarta has implemented a bigscale social restrictions policy for accelerating COVID-19 eradication since September 14, 2020, with references to Government Regulation No 88/2020. In the healthcare sector, this regulation implemented strict health protocol and limited the capacity to $50 \%$. It impacted Dharmais Cancer Hospital for the decrease of cases in October 2020. This policy was only an effort to control and reduce the number of cases. However, individual awareness in implementing health protocol and hygiene sanitation is essential for preventing the transmission of COVID-19 and protecting others.

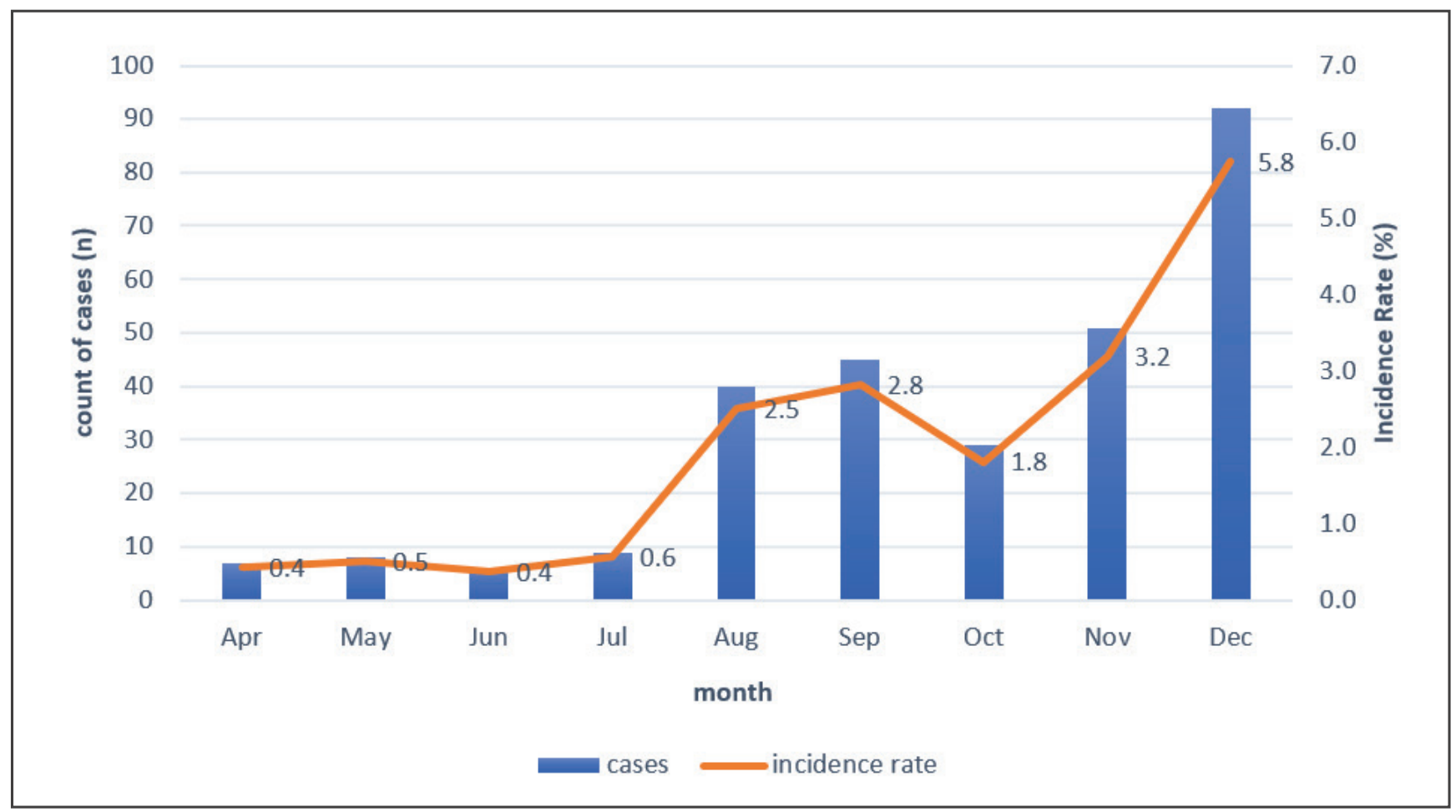

Figure 1. The cases of COVID-19 among health care workers in Dharmais Cancer Hospital

\author{
Corresponding author: \\ *Mutiara Adelina \\ Infection Prevention and Control Department, \\ Dharmais Cancer Hospital, Jakarta, Indonesia \\ ppirskd@gmail.com
}




\section{REFERENCES}

1. World Health Organization. Coronavirus disease (COVID-19) pandemic [Internet]. Coronavirus disease. 2020 [cited 2020 Jun 19]. Available from: https:// www.who.int/emergencies/diseases/novelcoronavirus-2019

2. Satuan Tugas COVID-19. Data sebaran situasi virus COVID-19 [Internet]. 2020 [cited 2021 Jan 5]. Available from: https://www.covid19.go.id/

3. Peng $X, X u X, L i Y$, et al. Transmission routes of 2019-nCoV and controls in dental practice. Int J Oral Sci. 2020;12(1):1-6.

4. Xiang $Y T$, Jin $Y$, Wang $Y$, et al. Tribute to health workers in China: A group of respectable population during the outbreak of the COVID-19. Int J Biol Sci. 2020;16(10):1739-40.

5. Chou R, Dana T, Buckley DI, et al. Epidemiology of and risk factors for coronavirus infection in health care workers: a living rapid review. Ann Intern Med. 2020;173(2):120-36.

6. Çelebi G, Pişkin N, Çelik Bekleviç A, Altunay $Y$, et al. Specific risk factors for SARS-CoV-2 transmission among health care workers in a university hospital. Am J Infect Control. 2020;48(10):1225-30.

7. Wang D, Hu B, Hu C, Zhu F, Liu X, Zhang J, et al. Clinical characteristics of 138 hospitalized patients with 2019 novel coronavirus-infected pneumonia in Wuhan, China. JAMA - J Am Med Assoc. 2020;323(11):1061-9.

8. Bergh MFQK, Suzan, Bentvelsen, et al. SARS-CoV-2 infection in 86 healthcare workers in two Dutch hospitals in March [Preprint]. 2020 [cited 2020 Jan 10]: [16 p.]. Available form: https://www.medrxiv. org/content/10.1101/2020.03.23.20041913v3

9. International Council Of Nurses. International Council of Nurses 2020: High proportion of healthcare workers with COVID19 [Internet]. Italy: International Council Of Nurses. 2020 [cited 2021 Feb 20]. Available form: https://www.icn.ch/sites/default/ files/inline-files/PR_09_COVID-19\%20-\%20Italy.pdf
10. McMichael TM, Currie DW, Clark S, et al. Epidemiology of Covid-19 in a long-term care facility in King County, Washington. N Engl J Med. 2020;382(21):2005-11.

11. Mhango $M$, Dzobo $M$, Chitungo I, Dzinamarira $T$. COVID-19 risk factors among health workers: a rapid review. Saf Health Work. 2020;11(3):262-5.

12. Liu M, He P, Liu HG, et al. Clinical characteristics of 30 medical workers infected with new coronavirus pneumonia. Eur PMC. 2020;43(0):16-22.

13. Ran L, Chen X, Wang Y, et al. Risk factors of healthcare workers with coronavirus disease 2019: a retrospective cohort study in a designated hospital of Wuhan in China. Clin Infect Dis. 2020;71(16):2218-21.

14. Schwartz J, King CC, Yen MY. Protecting healthcare workers during the coronavirus disease 2019 (covid-19) outbreak: Lessons from Taiwan's severe acute respiratory syndrome response. Clin Infect Dis. 2020;71(15):858-60.

15. Romano MR, Montericcio A, Montalbano C, et al. Facing COVID-19 in Ophthalmology Department. Curr Eye Res. 2020;45(6):653-8.

16. Barrett ES, Horton DB, Roy J, Gennaro ML, Brooks A, Tischfield J, et al. Prevalence of SARS-CoV-2 infection in previously undiagnosed health care workers in New Jersey, at the onset of the U.S. COVID-19 pandemic. BMC Infect Dis. 2020;20(1):20-7.

17. World Health Organization. WHO guideline on health policy and system support to optimize community health worker programmes [Internet]. Geneva: World Health Organization; 2018 [cited 2021 Feb 19]. [21-24 p.]. Available from: http://library1.nida. ac.th/termpaper6/sd/2554/19755.pdf

18. Kesehatan K. Pedoman Pencegahan dan Pengendalian Corona Virus deases (Covid-19). Kementrian Kesehat [Internet]. 2020 [cited 2021 Feb 19]. [178p.]. Available from: https://covid19.go.id/storage/app/ media/Protokol/REV-05_Pedoman_P2_COVID-19_13_ Juli_2020.pdf 